ARTICLE

DOI: $10.1038 / s 41467-017-02692-w$

\title{
Pteropods counter mechanical damage and dissolution through extensive shell repair
}

\author{
Victoria L. Peck ${ }^{1}$ Rosie L. Oakes (10) ${ }^{2,3}$, Elizabeth M. Harper ${ }^{4}$, Clara Manno ${ }^{1} \&$ Geraint A. Tarling ${ }^{1}$
}

The dissolution of the delicate shells of sea butterflies, or pteropods, has epitomised discussions regarding ecosystem vulnerability to ocean acidification over the last decade. However, a recent demonstration that the organic coating of the shell, the periostracum, is effective in inhibiting dissolution suggests that pteropod shells may not be as susceptible to ocean acidification as previously thought. Here we use micro-CT technology to show how, despite losing the entire thickness of the original shell in localised areas, specimens of polar species Limacina helicina maintain shell integrity by thickening the inner shell wall. One specimen collected within Fram Strait with a history of mechanical and dissolution damage generated four times the thickness of the original shell in repair material. The ability of pteropods to repair and maintain their shells, despite progressive loss, demonstrates a further resilience of these organisms to ocean acidification but at a likely metabolic cost.

\footnotetext{
${ }^{1}$ British Antarctic Survey, Natural Environment Research Council, High Cross, Madingley Road, Cambridge CB3 OET, UK. ${ }^{2}$ Department of Geosciences, The Pennsylvania State University, University Park, PA 16802, USA. ${ }^{3}$ Academy of Natural Sciences of Drexel University, 1900 Benjamin Franklin Parkway, Philadelphia, PA 19103, USA. ${ }^{4}$ Department of Earth Sciences, University of Cambridge, Downing Street, Cambridge CB2 3EQ, UK. Correspondence and requests for materials should be addressed to V.L.P. (email: vlp@bas.ac.uk)
} 
T he current rate of anthropogenic carbon release is unprecedented during the past 66 million years ${ }^{1}$, leading to acidification of the ocean through heightened uptake of $\mathrm{CO}_{2}$ into surface waters. In addition to decreasing $\mathrm{pH}$ values, ocean acidification diminishes the availability of carbonate ions, the building blocks of calcium carbonate, making calcification of shells and skeletons in marine organisms more energetically demanding and unprotected shells susceptible to dissolution ${ }^{2}$. Polar oceans are predicted to be among the first to become undersaturated with respect to carbonate ${ }^{3,4}$ and calcifying organisms living in the polar regions, especially those which make their shell from aragonite, the more soluble form of calcium carbonate, have been the focus of studies investigating the likely impact of ocean acidification. While polar benthic molluscs exhibit resilience to ocean acidification ${ }^{5}$, microscopic pelagic molluscs, pteropods, have been shown to decrease their rate of calcification $^{6-8}$ and exhibit shell dissolution within waters undersaturated with respect to aragonite, $\Omega_{\mathrm{Ar}} \leq 1^{2,9}, 10$. In a similar way to paint on a car protecting the metal body from exposure to the corrosive effects of the atmosphere, shelled molluscs, including pteropods, have an organic coating known as the periostracum protecting the shell from dissolution upon exposure to undersaturated waters ${ }^{11,12}$. Observations of rapid pteropod shell dissolution have been accounted for by the thin periostracum covering pteropod shells allowing dissolution to occur beneath it $^{13}$. However, a recent study finding that pteropods exposed to seasonally undersaturated waters were only vulnerable to shell dissolution where the periostracum had been damaged ${ }^{14}$ opened debate on the effectiveness of the pteropod periostracum ${ }^{15}, 16$. Accepting the notion that intact pteropod periostracum is effective in impeding dissolution, once damaged, for example, scratched by a predator or weakened by microbes, the underlying shell structure is no longer protected and exposure of aragonite to waters of $\Omega_{\mathrm{Ar}} \leq 1$ can lead to progressive shell dissolution ${ }^{14}$. If dissolution breaches the shell wall, the animal's ability to regulate buoyancy and internal chemistry is compromised and the soft body becomes vulnerable to infection and predation ${ }^{17}$. Internal repair of failed predation, endolith boring and other physical and chemical damage to the shell is common in molluscs through the secretion of carbonate onto the inner wall of the shell ${ }^{18-22}$. While previous studies have indicated that internal thickening of the shell is likely to be common to pteropods $^{8,14}$, the extent to which this process can protect these animals from the deleterious effects of exposure to undersaturated waters in the natural environment has not been observed.

In this study, we use micro-computed tomography (micro-CT) (cf. ref. ${ }^{23}$ ) to analyse damaged shells of polar species Limacina helicina collected within the Fram Strait. Shell thickness measurements across both pristine and damaged areas of shell reveal that specimens are able to maintain shell integrity by extensive thickening of the inner shell wall. The ability of L. helicina to repair shell damage in naturally undersaturated conditions indicates that this species has more potential to counteract the deleterious effects ocean acidification may have on their shells than previously considered.

\section{Results}

Damaged shells within Fram Strait sea ice. We analyse specimens of polar species $L$. helicina recovered during research expedition JR271 during June $2012^{14}$. Of the 28 stations where the British Antarctic Survey's motion-compensated bongo net was deployed, L. helicina were recovered at four localities, associated with some of the coldest waters encountered during the cruise (Supplementary Table 1; Supplementary Figs. 1, 2). At one of these stations (Station 18; Fig. 1), within sea ice in Fram Strait, a third (13) of the recovered pteropods $(n=36)$ exhibited notable shell damage not observed at the other sites (Supplementary Fig. 3). Three of the specimens exhibiting shell damage presented a history of trauma to the shell surface that caused deep damage in the inner whorls and exposure of the shells' internal microstructure.

Multi-image analysis determines the stages of damage and repair. Comparison of light microscopic, scanning electron microscopic (SEM) and CT scans (Fig. 2; but also see Supplementary Figs. 5 and 6) reveal a range of shell damage with varying stages of repair. Pristine shell appears translucent under light microscope (Fig. 2a), with smooth-surfaced subtle growth bands evident in SEM (Fig. 2c). There is little variability in the thickness of pristine shell, typically measuring $7-8 \mu \mathrm{m}$ (Fig. $2 \mathrm{~d}$; also ref. ${ }^{24}$ ). Anomalies within otherwise pristine shell include areas of deep outer surface damage (examples highlighted with black arrows in Fig. 2) within the inner whorls. The isosurface image (Fig. 2b) clearly highlights areas where the outer surface of the shell has been lost such that the current shell surface is recessed from the pristine shell surface. Cross-sections reveal that the depth of the deepest areas of damage exceeds the thickness of pristine shell (Fig. 3c, f) confirming that the original shell has been completely lost $^{14}$. The absence of a perforation in the shell, exposing the animal within, indicates that additional shell material has been secreted to 'patch up' the damaged area from the inside. This modification to the inner shell wall is readily evident, with areas adjacent to deep surface damage frequently over two times thicker than pristine shell (Fig. 3c, f). The site of deepest damage

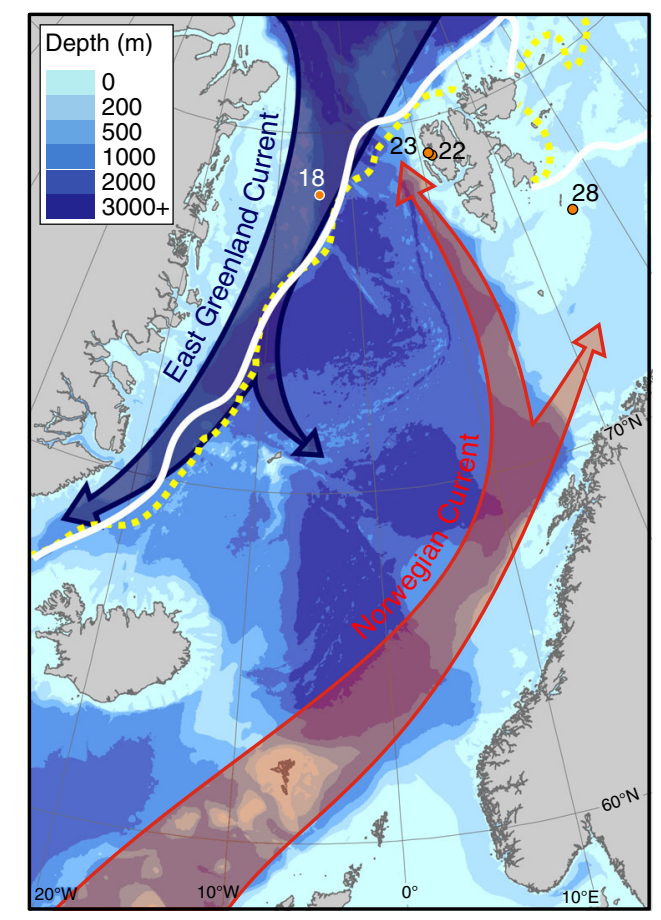

Fig. 1 Location of sites where L. helicina were collected in June 2012. Solid white line indicates the maximum sea ice extent in the preceding winter (March 2012 average). Dashed yellow line indicates the average position of the sea ice edge during June 2012 when the samples were collected. The East Greenland Current, flowing south out of the Arctic Ocean, is represented by a blue arrow. Atlantic waters, carried by the Norwegian Current, are represented by the red arrow. Bathymetry used is The GEBCO_2014 Grid, version 20150318, www.gebco.net. Sea ice extent data from the National Snow and Ice Data Centre 39 
in the illustrated specimen is $33 \mu \mathrm{m}$ below the original shell surface (Fig. 4a). Assuming an original shell thickness of $8 \mu \mathrm{m}$, this specimen generated over 4 times this thickness in repair material at this site of damage (Fig. $4 \mathrm{~b}$ ).

A further area of notable shell thickening is highlighted with a grey arrow in the penultimate whorl, corresponding to opacity under light microscope (Fig. 2). Despite this opacity, the SEM image reveals that there is no notable dissolution of the shell's outer surface (no aragonite rods exposed), but there are two relatively 'clean' historic fractures, possibly the result of more recent failed predation. It appears that the animal has built up shell material beneath these fractures effectively to weld the shell back together. The lack of surface dissolution but opacity in light microscope coincident with the area of shell thickening could indicate that areas of shell repair can also appear opaque in light microscope, perhaps on account of a different microstructure.

Within the final whorl, there is no evidence of surface dissolution or shell thickening; however, mechanical fractures and surface damage are evident, suggesting that dissolution and the repair response have not yet been initiated (Fig. 2; white arrows).

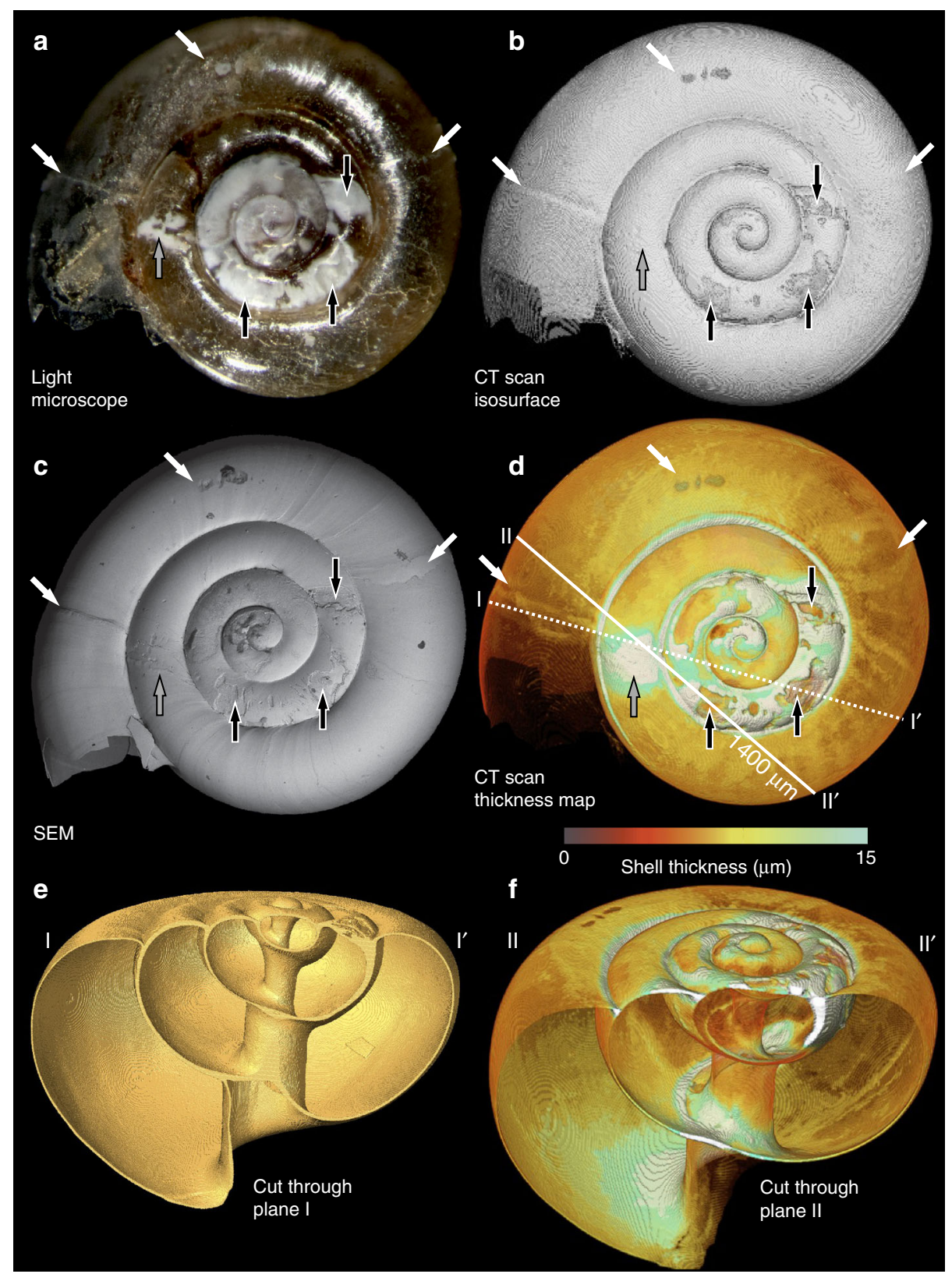

Fig. 2 Comparison of imaging methods of $L$. helicina specimen to demonstrate shell thickening in response to surface damage and dissolution. a Light microscopic image; $\mathbf{b}$ isosurface rendering of the surface of the shell; $\mathbf{c}$ SEM; $\mathbf{d}$ CT-scan thickness map; e, $\mathbf{f}$ cut-through images along planes I-I' and II-II' indicated in $\mathbf{d}$, respectively. The shell thickness colour scale used in $\mathbf{d}$ and $\mathbf{f}$ is indicated within the range 0-15 $\mu \mathrm{m}$. Shell exceeding a thickness of $15 \mu \mathrm{m}$ appears white. Black arrows indicate areas of deep surface damage in the inner whorls with evidence of dissolution and associated shell thickening observed in SEM and CT images, respectively. Grey arrow indicates shell fractures in the penultimate whorl with no evidence of dissolution but associated shell thickening observed. White arrows indicate fractures and mechanical damage in the final whorl with no evidence of dissolution and no associated shell thickening observed 


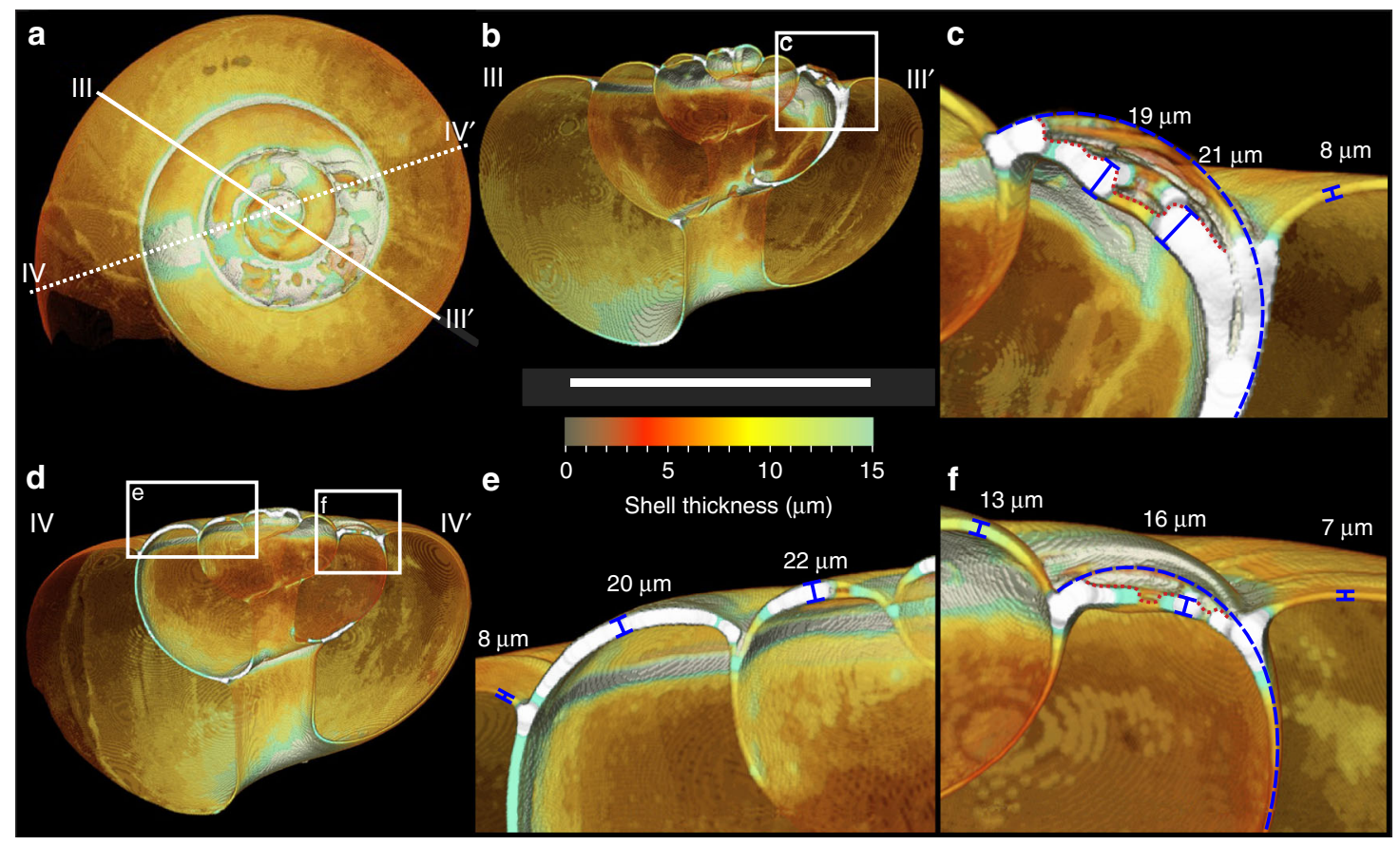

Fig. 3 Analysis of cross-sections to determine the extent of surface damage/dissolution and repair calcification. a CT-scan thickness map; $\mathbf{b}$ cross-section along plane III-III' shown in $\mathbf{a}$; $\mathbf{c}$ zoom-in on area indicated in $\mathbf{b}$; $\mathbf{d}$ cross-section along plane IV-IV' shown in $\mathbf{a}$; $\mathbf{d}$ and $\mathbf{e}$ zoom-ins on areas indicated in $\mathbf{d}$. White scale bar represents $1 \mathrm{~mm}$. The shell thickness colour scale is indicated within the range $0-15 \mu \mathrm{m}$. Shell exceeding a thickness of $15 \mu \mathrm{m}$ appears white. Point thickness measurements are indicated by blue barred lines (perpendicular to the outer surface). In $\mathbf{c}$ and $\mathbf{f}$, the blue dashed line indicates the position that the original shell surface would have occupied prior to damage, based on the profile of the undamaged shell of the same whorl in the background. The red dotted line indicates the current outer surface of the shell along the plane of the cross-section

\section{Discussion}

In many cases, initial damage to the shell is likely to have been mechanical in nature, on account of scratch-like features possibly indicative of failed predation attempts (Supplementary Fig. 4). The exposure of individual aragonite rods evident under SEM, however, is consistent with 'etching' observed following deliberate experimental exposure of pteropods to undersaturated waters ${ }^{2}, 9,10$. We therefore propose that aragonite exposed at sites of damage had been susceptible to dissolution by undersaturated waters secondarily, exacerbating the mechanical shell damage further. Continued exposure to undersaturated waters is the most plausible explanation for the extensive loss of repair material from the outer surface, necessitating the persistent thickening of the inner shell, at sites of deep damage (Fig. 4). The progressive loss of shell in these areas resulted from the inability of the animal to replace the periostracum (ref. ${ }^{11}$ and references therein), meaning that repair material remained unprotected and was subject to progressive dissolution on the outer surface. Despite this continued shell loss, the animal appears to have invested energy into maintaining a minimum shell thickness comparable with that of pristine shell. While the sub-sea-ice waters from which these specimens were collected had the lowest $\Omega_{\mathrm{Ar}}$ values encountered during the cruise, they were not undersaturated ${ }^{25}$ (Supplementary Fig. 2). We are not aware of any physical property or carbonate chemistry measurements beneath the sea ice in Fram Strait in the winter months that can validate our hypothesis that these specimens were exposed to undersaturated waters, but we do note that waters beneath sea ice in comparable, seasonal sea ice regions within the Arctic do become undersaturated during the winter months. The most comparable study area we found was in the Amundsen Gulf, where Fransson et al. ${ }^{26}$ measured under-ice-water conditions through the formation and subsequent melt of seasonal (first year) sea ice over winter $2007-2008$. $\Omega_{\mathrm{Ar}}$ was observed to decrease beneath the sea ice with minimum values (0.6-1.4) recorded in March/April 2008. Sea ice melt began in May and enhanced sea-air exchange and photosynthesis, drawing down $\mathrm{pCO}_{2}$, caused $\Omega_{\mathrm{Ar}}$ to increase to values of 1.4-2. These $\Omega_{\mathrm{Ar}}$ values recorded in the Amundsen Gulf in May are similar to those measured in waters beneath melting ice within the Fram Strait in June (Supplementary Table 1, Supplementary Figure 2). If we assume a similar seasonal range of $\Omega_{\mathrm{Ar}}$ beneath sea ice east of Greenland and the Amundsen Gulf, we can anticipate that waters at and around Station 18 were likely to have been close to saturation $\left(\Omega_{\mathrm{Ar}} \sim 1\right)$ or undersaturated $\left(\Omega_{\mathrm{Ar}}<1\right)$ over the winter of 2011-2012. Alternatively, these specimens may have been advected by the East Greenland Current from undersaturated waters in the Arctic Ocean. Given the evidence of shell dissolution and the likelihood of these specimens having been exposed to undersaturated waters within their life history, we consider shell damage to result from a combination of mechanical damage and subsequent dissolution of exposed aragonite.

To understand the time lines involved in shell damage, dissolution and the internal repair/thickening response, we consider the life cycle of L. helicina within Fram Strait. In this example, the pteropod would have been recruited during the spring/summer of 2011 and overwintered beneath the sea ice before collection in the summer of $2012^{14}$. We propose that the specimen survived at least one predation attempt, causing mechanical damage to the surface of the shell, before or during the winter months. We anticipate that $\Omega_{\mathrm{Ar}}$ decreased beneath the sea ice ${ }^{25}$ during the winter period accounting for the extensive, localised dissolution in areas of shell where aragonite had been exposed by mechanical damage. L. helicina are observed to suppress linear shell growth when food is scarce during the winter months ${ }^{10,27}$. Consistent with Lischka \& Riebesell ${ }^{29}$, we propose that overwinter calcification efforts were focussed on repair and maintenance of the shell from the inside. In spring time, we anticipate that photosynthesis and enhanced air-sea exchange (following sea ice melt) 


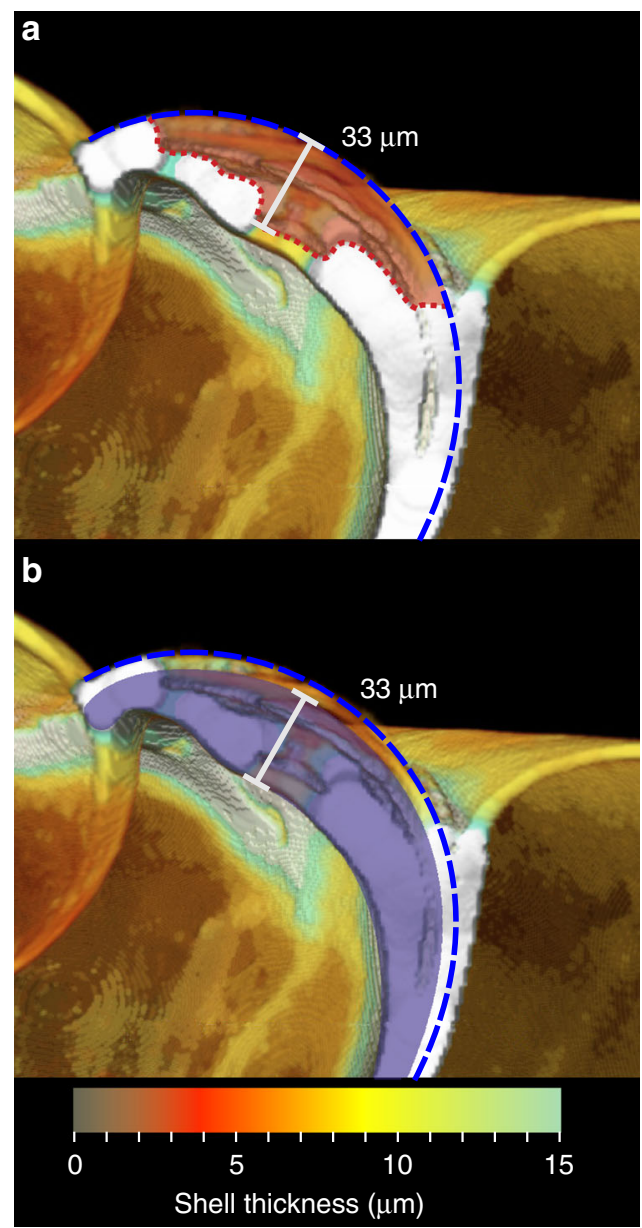

Fig. 4 Assessment of shell loss and thickening. Cross-section as Fig. 3c with blue dashed line indicating the original shell surface prior to damage/ dissolution. a The red shaded area indicates shell thickness lost between the original shell surface and the current shell surface (red dotted line). b The blue shaded area indicates shell thickening. Assuming an original shell thickness of $8 \mu \mathrm{m}$, this specimen has thickened the shell to a maximum of $33 \mu \mathrm{m}$ at this location

would have increased $\Omega_{\mathrm{Ar}}{ }^{26}$, reducing the progressive dissolution of exposed aragonite, allowing the animal to relax energy expended on shell maintenance. At the same time, enhanced food availability would have fuelled a surge in linear shell growth ${ }^{10,27}$, most likely represented by the near-pristine final whorl in our case study example (Fig. 2). The areas of fracture and mechanical damage on the last whorl would have only been vulnerable to dissolution during the following sea ice season when waters again became undersaturated, with extensive dissolution triggering the repair response.

Unlike specimens recovered from Fram Strait, L. helicina recovered from the outer region of Kongsfjord and the Barents Sea (Stations 22, 23 and 28) did not exhibit deep shell damage. However, shells collected at these stations do exhibit mechanical damage $^{14}$, which is consistent with our assumption that all populations would be exposed to comparable predatory pressures. The absence of shell opacity or 'etching' associated with historic fractures (Supplementary Fig. 3), however, indicates that, dissimilar to the Fram Strait specimens, dissolution at sites of mechanical damage did not occur to specimens from outerKongsfjord and the Barents Sea, suggesting that these specimens had not been exposed to undersaturated water. At the time of collection, $\Omega_{\mathrm{Ar}}$ exceeded 2 at Stations 22, 23 and 28. While waters at Station 18 (Fram Strait) were also oversaturated with respect to aragonite at the time of collection, we speculate that exposure to undersaturated waters likely occurred beneath sea ice during the preceding winter. We are confident that the specimens collected within Fram Strait overwintered on account of their shell diameter averaging $1255 \pm 146 \mu \mathrm{m}$. The shells of winged specimens (non-veligers) collected from outer-Kongsfjord and the Barents Sea had an average diameter of $753 \pm 145 \mu \mathrm{m}$ and $600 \pm 139 \mu \mathrm{m}$, respectively. The shell diameters of specimens from Stations 22, 23 and 28 are smaller than the $>900 \mu \mathrm{m}$ shell diameter typical of overwintering specimens studied within at NyAlesund ${ }^{10,27}$; however, we propose that it is more plausible that the outerKongsfjord and Barents Sea specimens were spawned in 2011 rather than just a few weeks prior to collection coincident with the spring bloom ${ }^{28}$. Despite the likelihood that specimens recovered from Stations 22, 23 and 28 had overwintered, we find little evidence to support them having been exposed to undersaturated waters. Although $\Omega_{\mathrm{Ar}}<1$ was observed at $200 \mathrm{~m}$ in the mid-fjord during February $2010^{10}$, waters in outer-Kongsfjord ${ }^{29}$ and the Barents $\mathrm{Sea}^{30}$ remain supersaturated with respect to aragonite during the winter months, consistent with the absence of dissolution damage observed in shells collected from these locations. The contrast in saturation state between Station 18 (Fram Strait) and the outer-Kongsfjord and Barents Sea stations can largely be attributed to regional oceanography and sea ice conditions (Fig. 1). The warm Atlantic waters transported within the Norwegian Current have a high total alkalinity ${ }^{31}$, which Comeau et al. ${ }^{32}$ considered to explain the relatively low sensitivity of western Svalbard waters to ocean acidification. The near absence of sea ice during the winter months at Stations 22, 23 and 28 further accounts for persistently supersaturated waters throughout the year. In contrast, the East Greenland Current, exporting Arctic waters, is cold with a low saturation state ${ }^{33}$. In addition, the presence of sea ice at Station 18 further modifies carbonate chemistry in sub-sea ice waters, decreasing $\Omega_{\mathrm{Ar}}$ over the winter months ${ }^{26}$, meaning Station 18 was likely close to saturation or undersaturated with respect to aragonite during the winter of 2011/2012. We conclude that the populations of $L$. helicina most susceptible to dissolution in areas of shell damage within the Greenland-Norwegian Arctic region are those in true polar waters, with sea ice playing a key role in decreasing the saturation state.

Sea ice seasons are doubly troublesome for these polar pteropods since exposed aragonite is progressively dissolved at the same time that food is scarce. In order to maintain the integrity of the shell during winter exposure to undersaturated waters, the rate of internal repair calcification would need to, at least, keep pace with the rate of dissolution (Fig. 4). Metabolic upregulation of overwintering L. helicina suggests that repair calcification is energetically demanding ${ }^{27}$, and we recognise the possibility that there may be a diminishing limit to the amount of damage that an animal is able to repair under further undersaturated conditions. While the extent of undersaturation, duration of exposure and incidence of periostracal damage are variables that may test the tolerance of L. helicina in this environment, the availability of food remains a key factor in driving the metabolic effort ${ }^{34}$. Considering that food is scarce over the winter months, we assume that stored energy reserves are used to fuel overwinter shell repair ${ }^{27}, 35$. Continuing reduction in sea ice cover will impact the quantity and timing of food availability in this region $^{36}$, which may benefit the ability of this species to balance their energy budgets ${ }^{35}$ over a shorter period of food scarcity. However, any benefit that a reduced sea ice season may offer will ultimately become redundant when light intensity becomes the limiting factor on controlling the onset of spring blooms, meaning L. helicina living in this environment will always endure 
periods of extreme food shortage as undersaturation becomes more pervasive ${ }^{4}$.

We note that it is unfortunate that the number of individuals we recovered exhibiting extensive damage and repair is so few. The restricted sample size is due to both the limited occurrence of pteropod populations with a history of likely exposure to undersaturated waters encountered along the cruise track and restricting time dedicated to zooplankton sampling when pteropods were present. However, the restricted sample size should not detract from the clear demonstration that L. helicina in the natural environment is able to thicken the shell wall and maintain shell integrity when the shell is damaged. L. helicina populations in environments where the incidence of shell damage is high and waters are, at least seasonally, undersaturated with respect to aragonite warrant further investigation and monitoring to better assess the impact and tolerances of L. helicina to undersaturated conditions, particularly during the winter months.

Our findings add to growing evidence that many polar calcifiers, exposed to undersaturated waters, can withstand and repair damage to their shells ${ }^{37}$, perhaps on account of natural exposure to heightened physical and chemical variability, which have resulted in organisms developing or exhibiting an inherent resilience strategy (cf. ref. ${ }^{38}$ ). We do not claim that L. helicina will be immune to ocean acidification on account of their ability to maintain their shells, but propose efforts should shift to assessing the metabolic cost of repair calcification when predicting the tolerance of this species to future environmental conditions.

\section{Methods}

Specimen collection and storage. Cruise JR271 consisted of 28 science days dedicated to obtaining a quantitative understanding of the impact of ocean acidification on the surface ocean biology and ecosystem and on the role of the surface ocean within the Arctic (https://www.bodc.ac.uk/resources/inventories/ cruise_inventory/report/11432/).

A comprehensive suite of routine sampling and measurements performed at stations each day prescribed a strict schedule for instrument deployment. Zooplankton collection on research expedition JR271 was primarily based on routine deployment of a motion-compensated Bongo net at 28 morning stations. The net (100 and $200 \mu \mathrm{m}$ mesh) was deployed between 0 and $200 \mathrm{~m}$ depth (water depth permitting) three times in succession (with the exception of sites where $L$. helicina was found where additional deployments were made where possible; see Supplementary Table 1), with one set of samples being immediately preserved (100 $\mu \mathrm{m}$ net sample preserved within ethanol and $200 \mu \mathrm{m}$ net in formalin for other analyses) and the two (or more) sets of samples used for hand picking copepods, pteropods and foraminifera for incubation or analysis. Once picked from the sample, specimens were rinsed in buffered milli-Q water on collection and air dried in individual wells within specimen slides. Dried specimens were imaged under light microscope to be catalogued and provide a means of assessing any postcollection damage to the shells. Shipboard images of L. helicina collected during JR271 are available (Supplementary Fig. 3).

Light microscope and SEM imaging. No additional preparation of the specimens was performed prior to light microscope or low-vacuum SEM imaging (Supplementary Fig. 4). For high-vacuum SEM imaging (Fig. 2, Supplementary Fig. 3) and CT scanning, specimens were sputter coated with $\sim 10 \mathrm{~nm}$ of gold-palladium.

CT scanning. Two specimens were scanned on a phoenix vltomelx $\mathrm{m}$ at $65 \mathrm{kV}$ and $230 \mu \mathrm{A}$ for $52 \mathrm{~min}$ at GE in Lewistown, PA. The resolution of this scan was $1 \mu \mathrm{m}$. One specimen was scanned on a FEI Quanta 650 SEM equipped with a Gatan X $\mu \mathrm{M}$ module at $22 \mathrm{kV}$, spot 6 , camera exposure $200 \mu$ s for one frame at the Natural History Museum, London. The resolution of this scan was $0.6 \mu \mathrm{m}$. Data were processed and visualised using VG Studio Max 2.2, Avizo 9.1, and ImageJ. Shell thickness was analysed using the BoneJ plug in for ImageJ. The resultant data were converted into greyscale (Greys lookup table) and exported as a .tiff stack. Shell thickness maps were created from this data in Avizo 9.1 using the VolRen thickness colour scheme set to a range of $0-0.015 \mathrm{~mm}$.

Data availability. All data are available from the authors upon request.

Received: 18 April 2017 Accepted: 19 December 2017

Published online: 17 January 2018

\section{References}

1. Zeebe, R. E., Ridgwell, A. \& Zachos, J. C. Anthropogenic carbon release rate unprecedented during the past 66 million years. Nat. Geosci. 9, 325-329 (2016).

2. Orr, J. C. et al. Anthropogenic ocean acidification over the twenty-first century and its impact on calcifying organisms. Nature 437, 681-686 (2005).

3. McNeil, B. I. \& Matear, R. J. Southern Ocean acidification: a tipping point at 450-ppm atmospheric $\mathrm{CO}_{2}$. Proc. Natl. Acad. Sci. USA 105, 18860-18864 (2008).

4. Steinacher, M. et al. Imminent ocean acidification in the Arctic projected with the NCAR global coupled carbon cycle-climate model. Biogeosciences $\mathbf{6}$, 515-533 (2009).

5. Schram, J. B., Schoenrock, K. M., McClintock, J. B., Amsler, C. D. \& Angus, R. A. Testing Antarctic resilience: the effects of elevated seawater temperature and decreased $\mathrm{pH}$ on two gastropod species. ICES J. Mar. Sci. 73, 739-752 (2016).

6. Comeau, S., Gorsky, G., Jeffree, R., Teyssié, J.-L. \& Gattuso, J.-P. Impact of ocean acidification on a key Arctic pelagic mollusc (Limacina helicina). Biogeosciences 6, 1877-1882 (2009).

7. Comeau, S., Jeffree, R., Teyssié, J. L. \& Gattuso, J. P. Response of the Arctic pteropod Limacina helicina to projected future environmental conditions. PLoS ONE 5, el1362 (2010).

8. Lischka, S., Budenbender, J., Boxhammer, T. \& Riebesell, U. Impact of ocean acidification and elevated temperatures on early juveniles of the polar shelled pteropod Limacina helicina: mortality, shell degradation, and shell growth. Biogeosciences 8, 919-932 (2011).

9. Bednarsek, N. et al. Extensive dissolution of live pteropods in the Southern Ocean. Nat. Geosci. 5, 881-885 (2012).

10. Lischka, S. \& Riebesell, U. Synergistic effects of ocean acidification and warming on overwintering pteropods in the Arctic. Glob. Change Biol. 18, 3517-3528 (2012).

11. Harper, E. M. The molluscan periostracum: an important constraint in bivalve evolution. Palaeontology 40, 71-97 (1997).

12. Tunnicliffe, V. et al. Survival of mussels in extremely acidic waters on a submarine volcano. Nat. Geosci. 2, 344-348 (2009).

13. Bednaršek, N. et al. Pteropods on the edge: cumulative effects of ocean acidification, warming, and deoxygenation. Prog. Oceanogr. 145, 1-24 (2016).

14. Peck, V. L., Tarling, G. A., Manno, C., Harper, E. M. \& Tynan, E. Outer organic layer and internal repair mechanism protects Pteropod Limacina helicina from ocean acidification. Deep Sea Res. II 127, 41-52 (2016).

15. Bednaršek, N., Johnson, J. \& Feely, R. A. Comment on Peck et al.: Vulnerability of pteropod (Limacina helicina) to ocean acidification: shell dissolution occurs despite an intact organic layer. Deep Sea Res. II 127, 53-56 (2016).

16. Peck, V. L., Tarling, G. A., Manno, C. \& Harper, E. M., Reply to comment by Bednarsek et al. Deep Sea Res. II 127, 57-59 (2016).

17. Vermeij, G. J. Traces and trends in predation with special reference to bivalve animals. Paleontology 26, 455-465 (1983).

18. Cadee, G. C. Shell damage and shell repair in the Antarctic limpet Nacella concinna from King George Island. J. Sea Res. 41, 149-161 (1999).

19. Dietl, G. P. Successful and unsuccessful predation of the gastropod Nucella lapillus (Muricidae) on the mussel Mytilus edulis from Maine. Veliger 43, 319-329 (2000).

20. Marshall, D. J. \& Day, R. W. Change in the rate of shell deposition and shell microstructure in response to shell borers in the abalone Haliotis rubra. Mar. Freshw. Behav. Physiol. 34, 189-195 (2001)

21. Harper, E. M. et al. Iceberg scour and shell damage in the Antarctic bivalve Laternula elliptica. PLoS ONE 7, e46341 (2012).

22. Langer, $\mathrm{G}$. et al. Limpets counteract ocean acidification induced shell corrosion by thickening of aragonitic shell layers. Biogeosciences 11, 7363-7368 (2014).

23. Howes, E. L., Eagle, R. A., Gattuso, J.-P. \& Bijma, J. Comparison of Mediterranean pteropod shell biometrics and ultrastructure from historical (1910 and 1921) and present day (2012) samples provides baseline for monitoring effects of global change. PLoS ONE 12, e0167891 (2017).

24. Sato-Okoshi, W., Okoshi, K., Sasaki, H. \& Akiha, F. Shell structure characteristics of pelagic and benthic molluscs from Antarctic waters. Polar Science 4, 257-261 (2010).

25. Tynan, E. et al. Physical and biogeochemical controls on the variability in surface $\mathrm{pH}$ and calcium carbonate saturation states in the Atlantic sectors of the Arctic and Southern Oceans. Deep Sea Res. 127, 7-27 (2016).

26. Fransson, A. et al. Impact of sea-ice processes on the carbonate system and ocean acidification at the ice-water interface of the Amundsen Gulf, Arctic Ocean. J. Geophys. Res. Oceans 1, 1-81 (2013).

27. Lischka, S. \& Riebesell, R. Metabolic response of Arctic pteropods to ocean acidification and warming during the polar night/twilight phase in Kongsfjord (Spitsbergen). Polar Biol. 40, 1211-1227 (2017).

28. Gannefors., C. et al. The Arctic sea butterfly Limacina helicina: lipids and life strategy. Mar. Biol. 147, 169-177 (2005).

29. Fransson, A. et al. Late winter-to-summer change in ocean acidification state in Kongsfjorden, with implications for calcifying organisms. Polar Biol. 39, 1841-1857 (2016). 
30. Tynan, E., Tyrrell, T. \& Achterberg, E. P. Controls on the seasonal variability of calcium carbonate saturation states in the Atlantic gateway to the Arctic Ocean. Mar. Chem. 158, 1-9 (2014).

31. Cottier, F. et al. Water mass modification in an Arctic fjord through cross-shelf exchange: the seasonal hydrography of Kongsfjorden, Svalbard. J. Geophys. Res. 110, C12005 (2005).

32. Comeau, S., Alliouane, S. \& Gattuso, J. P. Effects of ocean acidification on overwintering juvenile Arctic pteropods Limacina helicina. Mar. Ecol. Prog. Ser. 456, 279-284 (2012).

33. Anderson, L. G. et al. Export of calcium carbonate corrosive waters from the East Siberian Sea. Biogeosciences 14, 1811-1823 (2017).

34. Thomsen, J. et al. Food availability outweighs ocean acidification effects in juvenile Mytilus edulis: laboratory and field experiments. Glob. Change Biol. 19, 1017-1027 (2013).

35. Seibel, B. A., Maas, A. E. \& Dierssen, H. M. Energetic plasticity underlies a variable response to ocean acidification in the pteropod, Limacina helicina Antarctica. PLoS ONE 7, e30464 (2012).

36. Arrigo, K. R., van Dijken, G. L. \& Pabi, S. Impact of a shrinking Arctic ice cover on marine primary production. Geophys. Res. Lett. 35, L19603 (2008).

37. Cross, E. L., Peck, L. S. \& Harper, E. M. Ocean acidification does not impact shell growth or repair of the Antarctic brachiopod Liothyrella uva (Broderip, 1833). J. Exp. Mar. Bio. Ecol. 462, 29-35 (2015).

38. Capone, D. G. \& Hutchins, D. A. Microbial biogeochemistry of coastal upwelling regimes in a changing ocean. Nat. Geosci. 6, 711-717 (2013).

39. Fetterer, F., Knowles, K., Meier, W., Savoie, M. \& Windnagel, A. K. Sea Ice Index, Version 3. Updated daily. https://doi.org/10.7265/N5K072F8 [Accessed 01 June 2017], NSIDC (National Snow and Ice Data Center), Boulder, Colorado, USA, 2017.

\section{Acknowledgements}

We thank the captain and crew of the RRS James Clark Ross for enabling this research and PSO Ray Leakey. We are grateful for funding support from NERC, DEFRA and DECC to the pelagic consortium of the UK Ocean Acidification programme (Grant no. $\mathrm{NE} / \mathrm{H} 17348 / 1^{\star}$ ). Thank you to the Natural History Museum London and GE in Lewistown, PA for access to CT-imaging facilities.

\section{Author contributions}

V.L.P. conceptualised the project and wrote the manuscript. V.L.P. and G.A.T. carried out the fieldwork. R.L.O. carried out CT scans and analysis. R.L.O., E.M.H., C.M., and G. A.T. aided in interpretation and contributed to writing the manuscript.

\section{Additional information}

Supplementary Information accompanies this paper at https://doi.org/10.1038/s41467017-02692-w

Competing interests: The authors declare no competing financial interests.

Reprints and permission information is available online at http://npg.nature.com/ reprintsandpermissions/

Publisher's note: Springer Nature remains neutral with regard to jurisdictional claims in published maps and institutional affiliations.

\begin{abstract}
(c) (i) Open Access This article is licensed under a Creative Commons Attribution 4.0 International License, which permits use, sharing, adaptation, distribution and reproduction in any medium or format, as long as you give appropriate credit to the original author(s) and the source, provide a link to the Creative Commons license, and indicate if changes were made. The images or other third party material in this article are included in the article's Creative Commons license, unless indicated otherwise in a credit line to the material. If material is not included in the article's Creative Commons license and your intended use is not permitted by statutory regulation or exceeds the permitted use, you will need to obtain permission directly from the copyright holder. To view a copy of this license, visit http://creativecommons.org/ licenses/by/4.0/.
\end{abstract}

(C) The Author(s) 2018 